\title{
Reliability of Computer Simulation on Illuminance Level of Pendentive Dome Mosque in Comparison with On-Field Data Collection
}

\author{
Ahmad Sanusi Hassan ${ }^{1} \&$ Yasser Arab ${ }^{1}$ \\ ${ }^{1}$ School of Housing, Building and Planning, Universiti Sains Malaysia, USM, Penang, Malaysia \\ Correspondence: Ahmad Sanusi Hassan, School of Housing, Building and Planning, Universiti Sains Malaysia, \\ 11800 USM, Penang, Malaysia. Tel: 60-19-506-8260.E-mail: sanusi.usm@gmail.com
}

Received: February 4, 2014

Accepted: March 17, $2014 \quad$ Online Published: March 20, 2014

doi:10.5539/mas.v8n2p183

URL: http://dx.doi.org/10.5539/mas.v8n2p183

\begin{abstract}
This research study discusses the accuracy of 3dStudio Max Design software in simulating illuminance distribution on pendentive dome mosque design. The case study is the Federal Territory Mosque in Kuala Lumpur, Malaysia. The mosque has pendentive dome design similar to the design of the Ottoman mosques and Hagia Sophia in Istanbul, Turkey. The accuracy level is evaluated based on comparisons between the predicted software and the measured-on-site data on the illuminance distribution. Both field monitoring readings and computer simulations of the mosque interior (prayer hall) were collected and data logged during the winter solstice, the day when the sun was on a perimeter at its highest latitude at the Tropic of Capricorn $\left(23^{\circ} 26^{\prime} 16^{\prime \prime} \mathrm{S}\right)$ which occurred on 21st December 2013. The illuminance level was measured at five locations inside the mosque. Result of this study revealed similar readings between the measured on-field and predicted computer simulation data with small marginal value difference. This study suggests acceptable accuracy readings provided by $3 \mathrm{dStudio}$ Max Design software for lighting simulation.
\end{abstract}

Keywords: Illuminance level, 3dStudio Max Design, lux meter, manual measurement, computer simulation

\section{Introduction}

Reducing energy consumption on building design becomes increasingly an important issue and approach in sustainable built environment. Daylighting is recognized as a key strategy to achieve this goal by reducing the electric usage of air-conditioning inside the building in a tropical country, leading to energy saving (Alshaibani, 2001; Bodart \& De Herde, 2002; Ihm et al., 2009; Vartiainen, 2001; Hassan \& Arab, 2013). Besides, daylighting (indirect sunlight) is one of the main concerns by architects when designing a building in order to enhance visual quality of building interior spaces (Ahmet \& Joarder, 2007). The increasing number of studies have been conducted and emphasized on the importance of using daylighting in building design. Scholars have emphasized the importance of daylight design in indoor area (Hourani \& Hammad, 2012) which improves the productivity of the occupants in work place (Joarder et al., 2009; Nicklas \& Bailey, 1996; Heschong et al., 2002).

Due to the importance of daylighting in building design, it is necessary to generate the daylight readings in computer simulation to predict lighting performance on illuminance level in the building interior. With growing number of available computer simulation programs in recent years, they have witnessed a growing number of design practitioners who are looking for accurate results in their lighting simulation software. There are numbers of studies which have examined the accuracy of these softwares in recent years. These studies have examined the reliability of computer programs such as RADIANCE (Kim \& Chung, 2011; Ng et al., 2001; Galasiu \& Atif, 2002; Reinhart \& Walkenhorst, 2001) Superlite and Superlink (Galasiu \& Atif, 2002), and Energyplus (Shrestha \& Maxwell, 2011).

A common methodology on accurate measurement for the simulation program is by examining the level of differences between measured on-field data and computer simulation on illuminance level. This method is used in past studies determining accuracy level in Superlite, Superlink, and Radiance software (Galasiu \& Atif, 2002; Li \& Tsang, 2005). Taking the previous studies as a reference, this study attempts to examine the accuracy of $3 \mathrm{dStudio}$ Max Design in daylighting simulation of interior building spaces. The popularity of 3dStudio Max Design software among the architects is its ability in construction of modelling and $3 \mathrm{~d}$ visualization inside the building 
spaces. However many researchers might not be aware of the ability of this software in generating daylight simulation. In fact the program is able to create daylight analysis which could be helpful in understanding of proposed design projects by referring to illuminance level.

3dStudio Max Design provides comprehensive, integrated 3d modelling and rendering solution for video games developers, visual effect artists and graphic designers. It is a good solvent for architects, designers and civil engineers in getting in-depth understanding of how projects work before they were able to build the building (Ozler, 2008). The program also can be supported with an EnergyPlus weather data file (*.EPW), which provides the software with 30 years information about the local weather in the area of study. EnergyPlus weather file contains annual data for typical climatic conditions at a site, including ambient temperature, relative humidity, wind speed and direction, as well as direct and diffuse irradiances (Reinhart, Landry, \& Breton, 2009).

The program is also capable to calculate the daylight illuminance level and daylight factor in specific times in a year such as summer and winter solstices or any other particular time. Using the mental ray render engine to do the simulation and the flux method for calculation, it calculates light from all directions which comes through the openings and indirect light which include the reflected light from the walls, floor and ceiling. It also calculates the daylight factor based on the CIE (Commission Internationale de L'Eclairage) overcast sky and information from the weather data file (Reinhart et al., 2009).

\section{Methodology}

\subsection{Case Study}

As mentioned earlier, this study aims to examine computer simulation's accuracy level of 3dStudio Max Design software by examining the illuminance level of indoor spaces. The accuracy level will be tested based on a comparison of the results between 3dStudio Max Design's computer simulation and on-field data taken inside a prayer hall of the Federal Territory Mosque (Figure 1) in Kuala Lumpur, Malaysia as the case study. This mosque is located at $3^{\circ}$ North of the Equator. The mosque has Ottoman pendentive dome design. Ottoman pendentive dome is one of the mosque architectural roof style originated from Turkey and Balkan region in Europe. Its ultimate design was inspired by the Blue Mosque (also known as Sultan Ahmet Mosque) in Istanbul, Turkey (Hassan, Mazloomi, \& Omer, 2013; Mustafa \& Hassan, 2013). The roof of the main prayer hall consists of a huge dome with a diameter around $28 \mathrm{~m}$ and height about $43 \mathrm{~m}$ from the ground of its prayer hall. The dome of the Federal Territory Mosque is centred with an addition of three half domes constructed at its west, south and north. While the east is the mosque's entrance which is designed with decorated arched main gate and four small domes. The mosque has $47,000 \mathrm{~m}^{2}$ and can accommodate 17,000 people at the same time (Kuala Lumpur City Guide Malaysia, 2009).

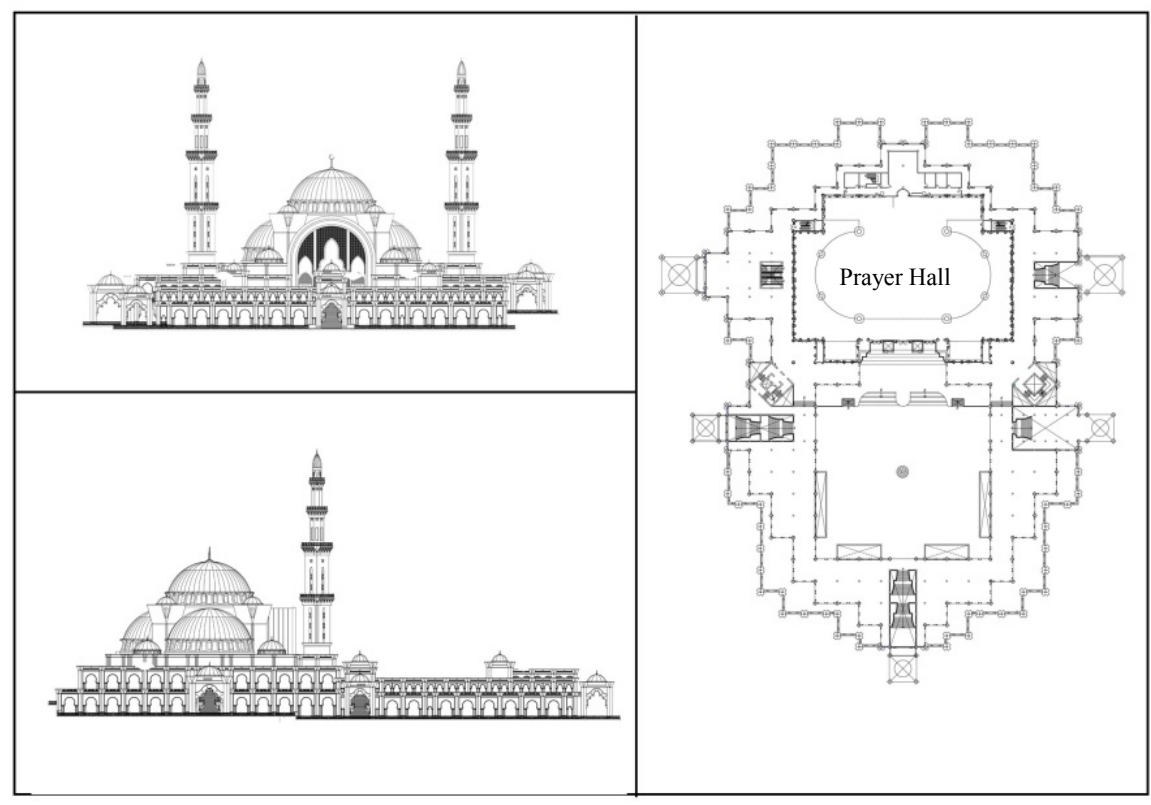

Figure 1. Federal Territory Mosque plan and elevations 


\subsection{Computer Simulation}

The lighting simulation data will be created using the computer software, 3dStudio Max Design 2013. The lighting source was taken as daylight, obtained from indirect and direct sunlight source, coming inside the building through the opening doors and windows. The other data is taken from on-field monitoring data inside the mosque using lux meter (daylight measuring tool) to measure the illuminance level in the prayer hall during the daytime from sunrise until sunset. Daylight simulation is a computer-based calculation of the lighting inside or outside the buildings (Marion Landry, 2009). The simulations are generated after the 3D model of the building was generated. Like on-field data measurements, these daylight simulations will be conducted every one hour from 6:00 am until 18:00 pm. To generate the results, this simulation involves the following steps (Hassan \& Arab, 2012; Arab \& Hassan, 2012, 2013):

Step 1. Draw Geometric Three Dimension Building in AutoCAD.

Step 2. Import Three Dimension Building into 3ds Max Design.

Step 3. Assign the Render.

Step 4. Create Daylight System.

Step 5. Import a weather data file (*.EPW) from EnergyPlus Energy Simulation Software.

Step 6. Create a Light Meter and place is in the specific position that gives the measurements in $1 \mathrm{~m} \times 1 \mathrm{~m}$ surface areas.

Step 7. Create a Camera and make a Simulation.

Step 8. The data of the illuminance level appears on the drawing.

\subsection{Manual Measurement}

Lux Meter used for the current study is Tecpel DLM-531 (Figure 2) which is a precise, easy to use digital lux meter ideal for measuring light levels applied to safety regulations, work areas and security lighting as illustrated in Table 1. Lux meter is a device for measuring brightness level, specifically measures the light intensity which appears to the human eye from the light source and reflection. Measuring this current allows the device to calculate the lux value which is the measurement unit of brightness. The main factor in this study is taking manual measurements of the amount of illuminance on $1 \mathrm{~m} \times 1 \mathrm{~m}$ surface area which is known as the illuminance levels (Runsheng, Meir, \& Etzion, 2009). The illuminance levels are classified in nine scales as shown in Table 2.

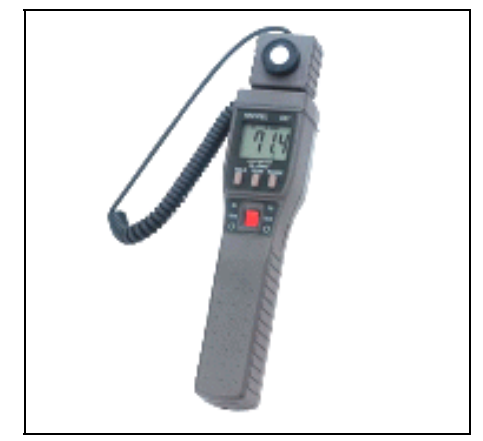

Figure 2. Tecpel DLM-531 
Table 1. Lux Meter (DLM-531) features

\begin{tabular}{cll}
\hline NO & Feature & Range \\
\hline 1 & Ranges & 20lux, 200lux, 2,000lux, 20,000lux; 20fc, 200fc, 2000fc, 20,000fc \\
2 & Resolution & $0.011 \mathrm{ux} . ; 0.01 \mathrm{fc}$ \\
3 & Spectral response & CIE photopic \\
4 & Acceptance angle & $\mathrm{f} 2<2 \%$ cosine corrected $(150 ?)$ \\
5 & Total accuracy for CIE standard & A $(2856 \mathrm{~K}) ;(+3 \%$ rdg+10dgts $)$ \\
6 & illuminate & 3 times/per second \\
7 & Gampling rate & Power Requirement: 4 pieces $1.5 \mathrm{~V}$ (AAA size) batteries \\
8 & Dimensions & $6.7 " x 1.7 " x 1.6 "(170 \times 44 \times 40 \mathrm{~mm})$ \\
9 & Weight & $311 \mathrm{~g}$ \\
\hline
\end{tabular}

Field manual measurements will be conducted on 21st December 2013 from 6:00 am to 18:00 pm taken in one hour interval. On this day the sun path is on perimeter at the Tropic of Capricorn (23 $\left.26^{\prime} 16^{\prime \prime} \mathrm{S}\right)$ latitude (TuTiempo, 2010). This day is the shortest day for the region located at the north of the Equator. Both of the measurements and simulation will be conducted at the same locations (Figure 2) in the mosque's prayer hall namely Point 1 (near the main entrance), Point 2 (centre), Point 3 (near mihrab), Point 4 (centre point of southern wall) and Point 5 (centre of northern wall). The lux meter will be placed at $450 \mathrm{~mm}$ high in the average body level of human chest while sitting on the floor inside the mosque.

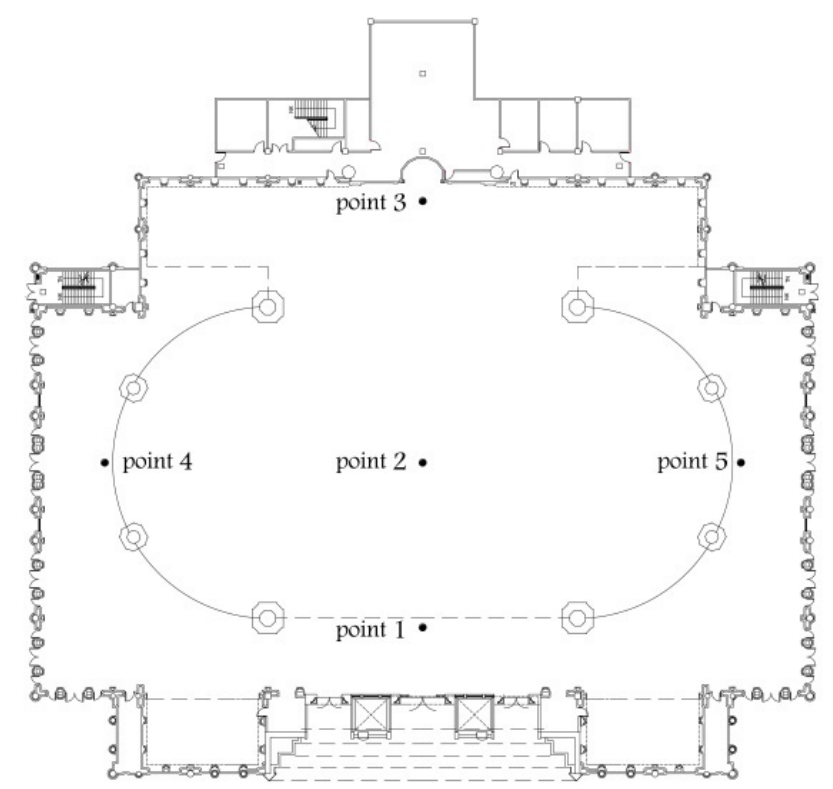

Figure 3. Selected 5 Points inside a prayer hall in the Federal Territory Mosque 
Table 2. Measurable scales of indoor lighting performance

\begin{tabular}{|c|c|c|}
\hline Scale & Ililluminance (lx) & Level \\
\hline 0 & $0-20$ & Total darkness to dark \\
\hline 1 & $20-49$ & Do not demand a high visibility of the task (public areas) \\
\hline 2 & $50-99$ & Do not demand a high visibility of the task (orientation during short stop) \\
\hline 3 & $100-199$ & $\begin{array}{l}\text { Do not demand a high visibility of the task (rooms not in permanent use and } \\
\text { hallway brightness) }\end{array}$ \\
\hline 4 & $200-499$ & Details easy to see at normal brightness for reading or office area \\
\hline 5 & $500-999$ & Details difficult to see like intricate work for brightness \\
\hline 6 & $1000-1999$ & $\begin{array}{l}\text { Tasklighting for highly demanding work - extremely fine details like } \\
\text { microelectronic assembly }\end{array}$ \\
\hline 7 & $2000-10000$ & $\begin{array}{l}\text { Tasklighting for highly demanding work - extremely fine details like special tasks } \\
\text { in surgery ( } 10000 \text { lux is maximum brightness from sunlight to indoor area) }\end{array}$ \\
\hline 8 & -100000 & Outdoor area brightness (100000 lux is the maximum measurement) \\
\hline
\end{tabular}

\section{Results of Analysis}

Both manual measurements and computer simulation were conducted on the 21st of December, 2013. The results were collected at hourly interval from $6: 00 \mathrm{am}$ to $6: 00 \mathrm{pm}$, and at the selected five points of the prayer hall. Table 3 the records illuminance levels of the manual measurements whereas Table 4 shows the results of the computer simulations at the five selected points inside the prayer hall. The results for manual measurement and the computer simulations are as follows:

Table 3. The Federal Territory Mosque's manual measurement results

\begin{tabular}{cccccccccccccc}
\hline Time & $\mathbf{6 : 0 0}$ & $\mathbf{7 : 0 0}$ & $\mathbf{8 : 0 0}$ & $\mathbf{9 : 0 0}$ & $\mathbf{1 0 : 0 0}$ & $\mathbf{1 1 : 0 0}$ & $\mathbf{1 2 : 0 0}$ & $\mathbf{1 3 : 0 0}$ & $\mathbf{1 4 : 0 0}$ & $\mathbf{1 5 : 0 0}$ & $\mathbf{1 6 : 0 0}$ & $\mathbf{1 7 : 0 0}$ & $\mathbf{1 8 : 0 0}$ \\
\hline P1 & - & - & 25 & 41 & 65 & 101 & 117 & 138 & 141 & 124.5 & 108 & 78 & 55 \\
P2 & - & - & 82 & 104 & 147 & 268 & 271 & 304 & 322 & 275 & 228 & 214 & 114 \\
P3 & - & - & 43 & 50 & 71 & 135 & 143 & 182 & 173 & 146 & 119 & 102 & 51 \\
P4 & - & - & 15 & 23 & 37 & 61 & 70 & 88 & 90 & 75 & 60 & 62 & 30 \\
P5 & - & - & 15 & 26 & 38 & 68 & 72 & 92 & 106 & 90 & 74 & 88 & 37 \\
\hline
\end{tabular}

Table 4. The Federal Territory Mosque's indoor computer simulation results

\begin{tabular}{cccccccccccccc}
\hline Time & $\mathbf{6 : 0 0}$ & $\mathbf{7 : 0 0}$ & $\mathbf{8 : 0 0}$ & $\mathbf{9 : 0 0}$ & $\mathbf{1 0 : 0 0}$ & $\mathbf{1 1 : 0 0}$ & $\mathbf{1 2 : 0 0}$ & $\mathbf{1 3 : 0 0}$ & $\mathbf{1 4 : 0 0}$ & $\mathbf{1 5 : 0 0}$ & $\mathbf{1 6 : 0 0}$ & $\mathbf{1 7 : 0 0}$ & $\mathbf{1 8 : 0 0}$ \\
\hline P1 & - & - & 31.7 & 71.5 & 112.3 & 126.8 & 133.7 & 130.5 & 121.4 & 104.8 & 77.9 & 43.7 & 9.1 \\
P2 & - & - & 74.6 & 166.8 & 244.8 & 299.8 & 336.4 & 338.6 & 320.6 & 272.4 & 198.3 & 113.5 & 22 \\
P3 & - & - & 60.3 & 120.7 & 173.1 & 207.5 & 233.2 & 239.3 & 229.6 & 195.9 & 144.5 & 79.8 & 15.9 \\
P4 & - & - & 20 & 37.2 & 55.2 & 66.8 & 71.2 & 73.1 & 69 & 60.6 & 44.5 & 26.6 & 5 \\
P5 & - & - & 24.3 & 57.2 & 80.8 & 94.8 & 101.3 & 100 & 88.9 & 73.8 & 54.8 & 31.3 & 6.3 \\
\hline
\end{tabular}

\subsection{Comparative Analysis}

Figures 4 to 9 illustrate the outcomes of both methods of analyses. The results of computer simulations and manual measurements are discussed in this section. The following illustrations offer detailed analyses of the comparative results between manual and simulation measurements:

\subsubsection{Point 1}

Figure 4 shows a line chart of manual and simulation measurement which had similar results. Point 1 had the third 
best illumination results using either method after Point 2 and 3. Most results were at Scale 3, followed by Scale 2 . The simulation results fluctuated in a range between 9.1 and 133.7 lux, whereas for the manual measurement the range of fluctuation was from 25 to 138 lux. The simulation results showed that the illuminance level started at 31.7 lux at 8:00 am, then rose gradually during the morning hours, reaching 71.5, 112.3, and 126.8 lux at 9:00, 10:00 and 11:00 am respectively, from Scale 2 to 3 in the afternoon. The curve then reached the peak of its brightness level at 12:00 pm with 133.7 lux. But after that, it started to decline progressively; from 1:00, 2:00 to 3:00pm, with Scale 3 at 130.5, 121.4 and 104.8 lux respectively, and from 4:00 and 5:00 pm to Scale 2 and 1 at 77.9 and 43.7 lux respectively. The minimum illuminance level was at 6:00 pm, with 9.1 lux (Scale 0).

The manual measurements revealed similar behaviour. It started at 25 lux at 8:00 am and then increased to 42, 65, 101, 117 and 138 lux at 9:00, 10:00, 11:00, 12:00 am and 1:00 pm, respectively. It reached its highest level at 2:00 $\mathrm{pm}$, with 141 lux. After 2:00 pm, the illuminance level began to decrease steadily, from 124.5, 108 to 78 lux at 3:00, 4:00 and 5:00 pm respectively. The curve diminished to $55 \mathrm{lux}$ at 6:00 pm. In both methods, the findings showed that the noon hours had brighter illuminance level than those in the morning and evening hours. The illuminance levels of computer simulations were classified under Scale 2 in the morning and evening hours at 8:00 am and 5:00 $\mathrm{pm}$. At 9:00am and 5:00pm, they were categorized under Scale 1 and 2. At 6:00 pm the brightness level is under Scale 1. Finally, the noon hours from 11:00 am to 3:00 pm were classified under Scale 3. The results of manual measurements go under Scale 1 at 8:00 and 9:00 am, and Scale 2 at 9:00 and 10:00 am, besides at 5:00 and 6:00 pm. From 11:00 am to 4:00 pm, the brightness levels were under Scale 3.

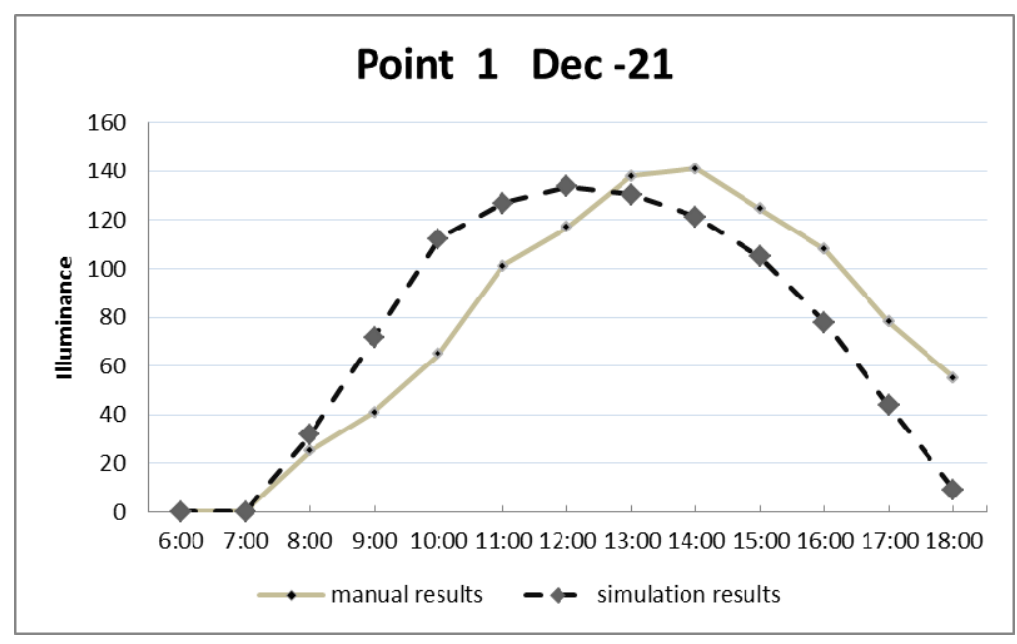

Figure 4. Line chart of Point 1

\subsubsection{Point 2}

Figure 5 illustrates the line chart of Point 2 located at the centre of prayer hall. It shows that the illuminance levels had similar result either generated by computer simulation or taken by manual measurements. Measurements at Point 2 had the overall highest brightness level, compared to Point 1,3,4 and 5. This area received the most efficient daylighting, due to the sunlit factor from all directions of the upper windows around the side of the pendentive dome (Hassan \& Bakhlah, 2013). Most results are at Scale 4 from 10:00 am to 3:00 pm. The computer simulation had a line chart started with 74.6 lux under Scale 2 at 8:00 am, then had a gradual increase from 166.8 lux at 9:00 am under Scale 3, to 244.8, 299.8 and 336.4 lux under Scale 4 at 10:00, 11:00 and 12:00 am respectively, and finally reached the maximum illuminance level at 1:00 pm, with 338.6 lux (Scale 4). The measurement after that declined from 2:00 and 3:00 pm to 4:00 and 5:00 pm, from 320.6 and 272.4 lux under Scale 4 to 198.3 and 113.5 lux under Scale 3. The lowest illuminance level was at 6:00 pm, with 22 lux (Scale 1). Similar line chart pattern was for the manual measurements, starting at 8:00 am with 82 lux under Scale 2, with gradual increases in the next 2 hours (9:00 and 10:00 am) from 104 and 147 lux under Scale 3 before reaching Scale 4 from 11:00 am to 5:00 pm with 268, 271, 304, 322, 275, 228 and 214 lux respectively. It has the highest illuminance level at $2.00 \mathrm{pm}$ with 322 lux. The graph line finally decreased to 114 lux (Scale 3) at 6:00 pm. 


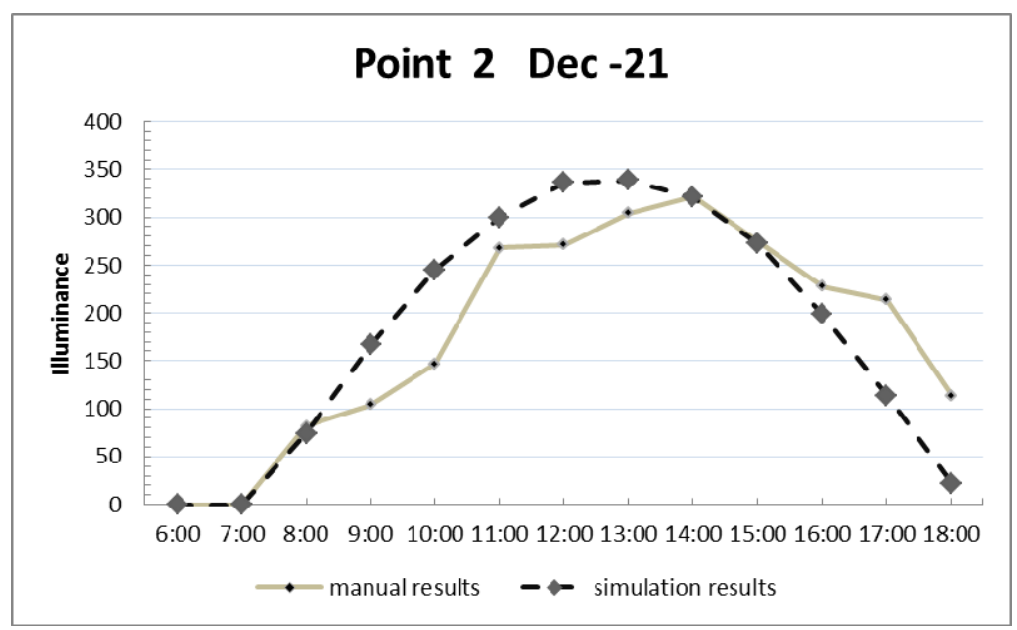

Figure 5. Line chart of Point 2

\subsubsection{Point 3}

Figure 6 illustrates a line chart of computer simulation and manual measurements at Point 3 located near the mihrab at which five times a day, the congregational prayers are normally held in this area. Most results of the illuminance levels taken at this location are under Scale 2 and 3. The simulation results showed that the illuminance levels are fluctuating from its lowest level at 15.9 lux (Scale 0) to its highest level at 239.3 lux (Scale 4). The line chart started at 8:00am with $60.3 \mathrm{lux}$ (Scale 2), then it had a gradual increase during the morning hours from 9:00 am (120.7 lux) and 10:00 am (173.1 lux) under Scale 3 to 11:00 am and 12:00 am with 207.5 and 233.2 lux respectively under Scale 4, before reaching its maximum illuminance level at 1:00 pm with 239.3 lux; and then at 2:00 pm having a slight decrease to 229.6 lux under Scale 4. After that, the graph line had a gradual decrease from 3:00 pm and 4:00 pm to 5:00 pm with 195.9 and 144.5 lux under Scale 3, to 79.8 lux under Scale 2 respectively. At 6:00 pm, it reached its minimum level with 15.9 lux (Scale 1). The manual measurements had similar results, with just a slightly lower illuminance level in comparison to the simulation results, as follows: Scale 1 at 8:00 am, Scale 2 at 9:00 am, 10:00 am and 6:00 pm, and Scale 3 from 11:00 am to 5:00 pm.

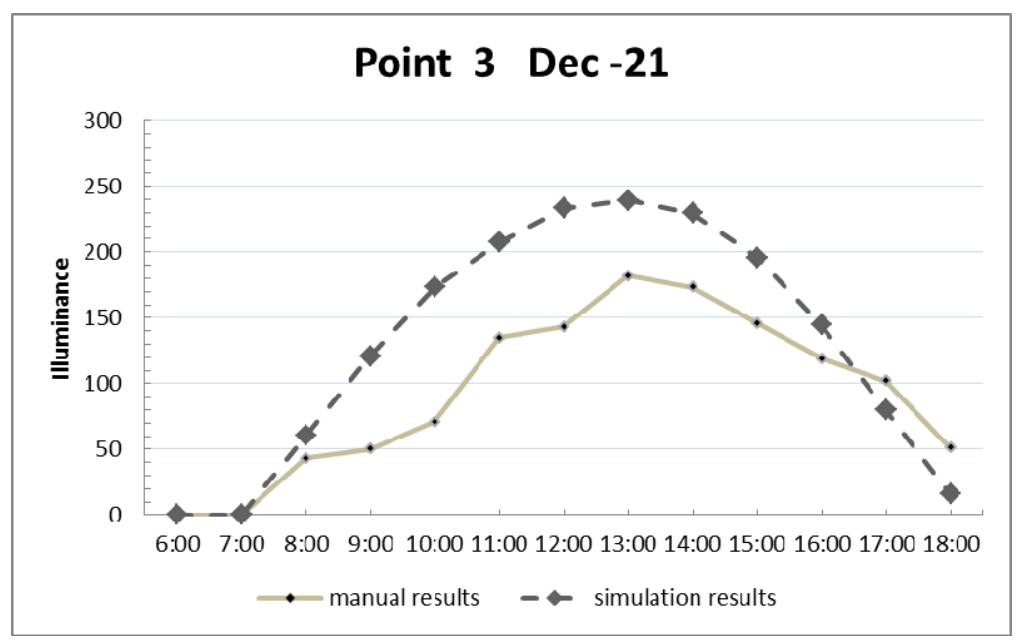

Figure 6. Line chart of Point 3

\subsubsection{Point 4}

Figure 7 shows a line chart at Point 4 (the middle of south wall) which clearly illustrates that both computer simulation and manual measurements had a similar pattern of illumination level during the daytime. Point 4 had the lowest lighting performance in this analysis. Most results were under Scale 2, and not a single illuminance level was fallen under Scale 3. In computer simulations, it started with 20 lux at 8:00 am. After that, it had a gradual increase, with 37.2, 55.2, 66.8 and 71.2 lux at 9:00, 10:00, 11:00 and 12:00 am under Scale 1 and 2. The highest 
illumination was only 73.1 lux at 1:00 pm; after that it had a steady decline from 69, 60.6 and 44.5 lux (2:00 to 4:00 $\mathrm{pm})$ to $26.6 \mathrm{lux}(5: 00 \mathrm{pm})$, finally reaching its lowest illumination of 5 lux at $6.00 \mathrm{pm}$. The manual measurement had a minimum illuminance level of 15 lux at 8:00 am, which increased gradually from 9:00 am with 23, 37, 61, 70 and 88 lux at 1:00 pm. It reached its highest illumination of 90 lux at 2:00 pm. After 2:00 pm, the illumination had gradual drops from 75, 60 and 53 to 30 lux at 6:00 pm.

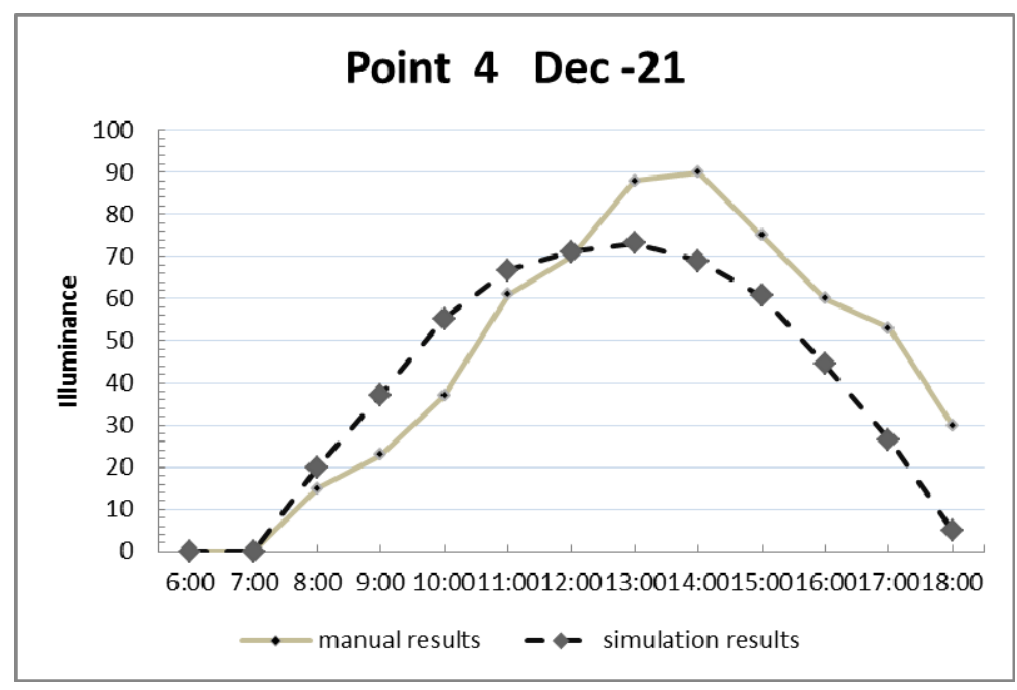

Figure 7. Line chart of Point 4

\subsubsection{Point 5}

The overall results from computer simulation and manual measurement are illustrated in Figure 8 . Both methods had approximately similar results. However like Point 4, Point 5 had poor illumination in this analysis. Most results were under Scale 2, with only a few hours of illumination under Scale 4. The computer simulations assigned at 8:00 am had 24.3 lux. The results then showed gradual increase from the morning to afternoon hours, from 9:00 to 12:00 am (57.2 to 101.3 lux). Afterthat, the illuminance levels had a drop from the afternoon hour to 5:00pm, from 100 to 31.3 lux. The maximum illuminance level was at $12.00 \mathrm{am}$, with 101.3 lux, and its minimum illuminance level was at 6:00 pm, with 22 lux. Similar graph pattern was traced with the manual measurements. For instance, the illuminance level at 8:00 am was 15 lux. The measurement then had an increase for the next 5 hours, to 1:00 pm, from 26 to 92 lux. At 2:00 pm, it had it highest illumination with 106 lux, before having a steady decline from 90 lux at 3:00 pm to 37 lux at 6:00 pm.

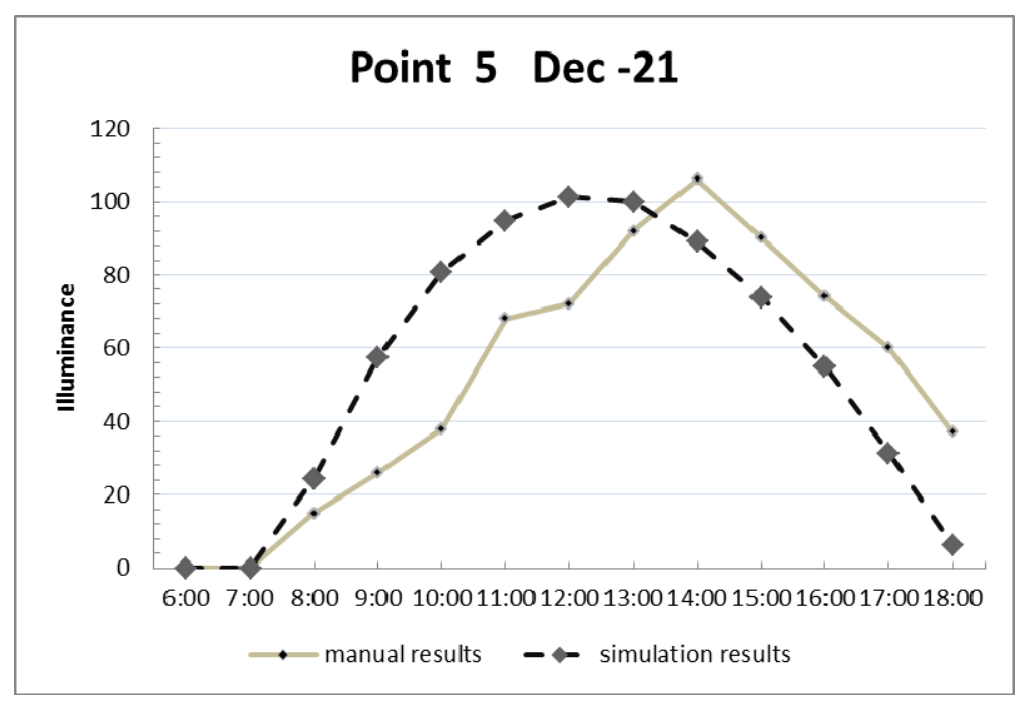

Figure 8. Line chart of Point 5 


\section{Discussion}

After having a comparative analysis on the results of illuminance level between computer simulation and manual measurement, the results have proved accuracy of computer simulation generated by 3dStudio Max Design software. The use of weather database from an EnergyPlus weather data file (*.EPW), which provides the software with 30 years information about the local weather for the area of study is very reliable. The co-related research findings show that the Federal Territory Mosque has good illuminance levels at Point 1, 2 and 3 but it has less satisfactory illuminance level at Point 4 and 5. Figures 5 to 8 , Table 2 and 3 show that the mosque design provides good illuminance levels during the daytime between 9:00 am and 4:00 pm at Point 1,2 and 3 which are categorized under Scales 3, 4 and 5 appropriate for brightness ranging from which do not demand a high visibility to normal illuminance level for reading activity (Hassan \& Arab, 2012). This study also finds that the average results of computer simulation and manual measurement are relatively similar to each other at Point 1 , to 5 . The computer simulation recorded an average of 87.6 lux from 8:00am to 6:00 pm at Point 1,217.1 lux at Point 2, 154.5 lux at Point 3, 48.1 lux at Point 4 and 64.9 lux at Point 5 in comparison to 90.3, 211.7, 110.5, 55.5 and 64.2 lux for Points $1,2,3,4$ and 5 respectively for manual measurements. The overall differences are ranging from 0.7 to 7.4 lux except at Point 3 with 44 lux. All the line charts shows that manual measurement had slightly lower values in the morning hours but it had slightly higher values in the evening hours compared to the values generated in computer simulation except at Point 3. It is the reason why Point 3 had the highest value differences in this analysis.

\section{Conclusion}

With the use of 3dStudio Max Design in generating the daylight level before construction helps the architects able to design the building and to avoid many problems in relation to daylighting design. There are presently various types of softwares for computing simulation in predicting how the building will perform before and after its construction, and 3dStudio Max Design is one of these softwares. This study, in conclusion, determines that the computer software 3dStudio Max Design is very reliable for obtaining data of the illuminance level of indoor areas through generating simulation of $3 \mathrm{~d}$ building drawings when combined with local weather data file entries to create daylight information. These results besides provide adequate basis for the researchers to use this computer software for building design analysis. This software can also amplify imagination of developments for the lighting functions, as it can help architects to understand how to provide the efficient brightness levels for every indoor space, in order to suit to the purpose and function of the activities inside the building.

\section{Acknowledgement}

This paper is from a research study under Research University Grant supported by Universiti Sains Malaysia.

\section{References}

Alshaibani, K. (2001). Potentiality of daylighting in a maritime desert climate: the Eastern coast of Saudi Arabia. Renewable Energy, 23(2), 325-331. http://dx.doi.org/10.1016/S0960-1481(00)00166-X

Arab, Y., \& Hassan, A. S. (2012). Daylighting Analysis of Pedentive Dome's Mosque Design during Summer Solstice with Case Studies in Istanbul, Turkey. International Transaction Journal of Engineering, Management, \& Applied Sciences \& Technologies, 3(2), 167-183.

Arab, Y., \& Hassan, A. S. (2013). Daylight Performance of Single Pedentive Dome Mosque Design During Winter Solstice. American Journal of Environmental Science, 9(1), 25-32. http://dx.doi.org/10.3844/ajessp.2013.25.32

Bodart, M., \& De Herde, A. (2002). Global energy savings in offices buildings by the use of daylighting. Energy and Buildings, 34(5), 421-429. http://dx.doi.org/10.1016/S0378-7788(01)00117-7

Digital-meters. (2011). Retrieved from http://www.digital-meters.com

EnergyPlus. (n.d.). Energy Simulation Software. Retrieved from http://apps1.eere.energy.gov/buildings/ energyplus/cfm/weather_data.cfm

Galasiu, A. D., \& Atif, M. R. (2002). Applicability of daylighting computer modeling in real case studies: comparison between measured and simulated daylight availability and lighting consumption. Building and Environment, 37(4), 363-377. http://dx.doi.org/10.1016/S0360-1323(01)00042-7

Hassan, A. S. \& Arab, Y. (2012). Lighting Analysis of Single Pendentive Dome Mosque Design in Sarajevo and Istanbul during Summer Solstice. The Arab World Geographer, 15(2), 163-179.

Hassan, A. S., \& Arab, Y. (2013). Analysis of Lighting Performance between Single Dome and Pyramid Roof Mosque in Mostar, Bosnia Herzegovina. Procedia Social and Behavioural Sciences, 91, 1-12. 
http://dx.doi.org/10.1016/j.sbspro.2013.08.395

Hassan, A. S., \& Bakhlah, M. S. O. (2013). Shading Analysis on Front Facade of Modern Terraced House Type in Petaling Jaya, Malaysia. Procedia Social and Behavioural Sciences, 91, 13-27. http://dx.doi.org/10.1016/j.sbspro.2013.08.396

Hassan, A. S., Mazloomi, M., \& Omer, S. (2013). Evolution of Pedentive Dome Design From Section View. In A. S. Hassan \& S. Omer, (Eds.), From Anatolia to Bosnia: Perspectives on Pedentive Dome Mosque Architecture (pp. 89-121). Penang: USM Press.

Hourani, M. M., \& Hammad, R. N. (2012). Impact of daylight quality on architectural space dynamics: Case study: City Mall - Amman, Jordan. Renewable and Sustainable Energy Reviews, 16(6), 3579-3585. http://dx.doi.org/10.1016/j.rser.2012.02.074

Ihm, P., Nemri, A., \& Krarti, M. (2009). Estimation of lighting energy savings from daylighting. Building and Environment, 44(3), 509-514. http://dx.doi.org/10.1016/j.buildenv.2008.04.016

Kim, C. S., \& Chung, S. J. (2011). Daylighting simulation as an architectural design process in museums installed with toplights. Building and Environment, 46(1), 210-222. http://dx.doi.org/10.1016/j.buildenv.2010.07.015

Kuala Lumpur City Guide - Malaysia. (2009, November 26). Retrieved from http://kualalumpurcityguide.com/

Marion Landry, P. F. (2009). Daylight simulation in Autodesk 3dStudio Max Design 2009.

Mustafa, F. A., \& Hassan, A. S. (2013). Mosque Layout Design: An Analytical Study of Mosque Layout in the early Ottoman Period. Frontiers of Architectural Research, 2(4), 445-456. http://dx.doi.org/10.1016/j.foar.2013.08.005

Network. (n.d.). Retrieved from http://www.dexigner.com/design_news/autodesk-3ds-max-design-2009.html

Ng, E. Y. Y., Poh, L. K., Wei, W., \& Nagakura, T. (2001). Advanced lighting simulation in architectural design in the tropics. Automation in Construction, 10(3), 365-379. http://dx.doi.org/10.1016/S0926-5805(00)00053-4

Reinhart, C. F., \& Walkenhorst, O. (2001). Validation of dynamic RADIANCE-based daylight simulations for a test office with external blinds. Energy and Buildings, 33(7), 683-697. http://dx.doi.org/10.1016/S0378-7788(01)00058-5

Runsheng, T., Meir, I. A., \& Etzion, Y. (2009). An analysis of absorbed radiation by domed and vaulted roofs as compared with flat roofs. Energy and Buildings, 35(6), 539-548. http://dx.doi.org/10.1016/S0378-7788(02)00165-2

Shrestha, S., \& Maxwell, G. (2011, 14-16 November). Emperical validation of building energy simulation software: Energrplus. Paper presented at the 12th Conference of International Building Performance Simulation Association, Sydney.

TuTiempo. (2010). Retrieved November 1, 2010, from http://www.tutiempo.net/en/Climate/Mostar/06-2010/ 133480.htm

Vartiainen, E. (2001). Electricity benefits of daylighting and photovoltaic for various solar facade layouts in office buildings. Energy and Buildings, 33(2), 113-120. http://dx.doi.org/10.1016/S0378-7788(00)00073-6

Wikipedia. (2013, December 10). Lux. Retrieved from http://www.en.wikipedia.org/wiki/Lux\#cite_note-3

\section{Copyrights}

Copyright for this article is retained by the author(s), with first publication rights granted to the journal.

This is an open-access article distributed under the terms and conditions of the Creative Commons Attribution license (http://creativecommons.org/licenses/by/3.0/). 